\title{
AS MEDIDAS ADOTADAS NO SISTEMA PENITENCIÁRIO FEDERAL NO COMBATE À PANDEMIA DE COVID-19
}

\author{
T. A. L. DE SOUSA \\ Universidade de Brasília \\ ORCID ID: https://orcid.org/0000-0002-8648-7555 \\ aluisio83@outlook.com
}

Submetido $17 / 08 / 2020$ - Aceito $23 / 11 / 2020$

DOI: 10.15628/holos.2020.10993

\section{RESUMO}

O novo coronavírus desencadeia a doença denominada COVID-19 (também conhecida como Sars-Cov-22), de grande capacidade de propagação e potencial letal. A presente pesquisa examina o conteúdo das regulamentações expedidas no âmbito do Sistema Penitenciário Federal a respeito da doença com o objetivo de discutir as ações e medidas de prevenção adotadas pelo Sistema Prisional Brasileiro a fim de evitar a contaminação em massa de presos e funcionários. Propõe ainda, analisar a maneira como a gestão pública enfrenta a atual crise e ao mesmo tempo garante tratamento e condições humanitárias aos funcionários, detentos e demais cooperadores. A pesquisa bibliográfica, de abordagem qualitativa-descritiva, procedeu à busca de artigos em portais de periódicos acadêmicos para compreender e traçar o panorama atual da doença. Assim, descobriu-se que inúmeras medidas foram adotadas pelo Brasil para evitar a sua disseminação, tais como a suspensão de visitas sociais, assistência jurídica e atividades educacionais, religiosas e de trabalho; a realocação de valores do fundo penitenciário e a liberação de presos idosos e portadores de doenças crônicas.

PALAVRAS-CHAVE: Penitenciárias. Gestão pública. Novo coronavírus. Plano de contingência.

\section{THE MEASURES ADOPTED IN THE FEDERAL PENITENTIARY SYSTEM IN COMBATING THE COVID-19 PANDEMIC}

\begin{abstract}
The new coronavirus start the disease called COVID-19 (also known as Sars-Cov-22), which has a great capacity for propagation and a lethal potential. This research examines the content of the regulations issued within the scope of the Federal Penitentiary System regarding the disease with the objective of discussing the preventive actions and measures adopted by the Brazilian Prison System in order to avoid the mass contamination of prisoners and employees. It also proposes to analyze the way in which public management faces the current crisis and at the same time guarantees treatment and humanitarian conditions to employees, detainees and
\end{abstract}

other cooperators. Bibliographic research, with a qualitative-descriptive approach, proceeded to search for articles in academic journals' portals to understand and outline the current panorama of the disease. In this way, it was discovered that numerous measures were adopted by Brazil to prevent its spread, such as the suspension of social visits, legal assistance and educational, religious and work activities; the reallocation of values from the prison fund and the release of seniors prisoners and those with chronic diseases.

KEYWORDS: Penitentiary. Public Management. New coronavirus. Contingency plan. 


\section{APRESENTAÇÃO}

A presente pesquisa tem por objetivo discutir as ações e políticas públicas adotadas pelo Brasil a fim de elaborar um plano de resposta à pandemia de COVID-19 dentro do sistema carcerário, mais especificadamente no Sistema Penitenciário Federal. Para tanto, utiliza-se de pesquisa bibliográfica qualitativa e descritiva para compreender a doença, o atual cenário das instalações presidiárias e os riscos que afligem a população carcerária, averiguando igualmente dados e números de outros países a respeito da contaminação em sistemas prisionais, além de estudar a legislação interna brasileira que estabelece um plano de contingência.

Esta pesquisa busca coletar e analisar informações sobre as medidas adotadas pela gestão pública para enfrentar a atual crise, estuda o conteúdo dos atos normativos expedidos que visam garantir os direitos fundamentais constitucionais assegurados aos funcionários e detentos no momento da epidemia e ainda, se existe um número suficiente de medidas e se tais medidas se mostram adequadas para atingir a finalidade almejada.

Portanto, nas sessões iniciais apresenta-se a metodologia utilizada, e, em seguida, na terceira sessão, exibe-se a situação das instalações prisionais, alguns dados e as medidas de contingência que podem ser aplicadas, adentrando em um estudo comparado com outros países. Os resultados e discussões, apresentados na quarta sessão, envolve a descrição e análise das principais regulamentações aplicadas no sistema prisional como um todo, afunilando para as ações e procedimentos aplicados em sedes de estabelecimentos federais, partindo-se, em seguida, para a conclusão da presente pesquisa.

\section{METODOLOGIA}

Trata-se de uma pesquisa bibliográfica, aplicada, qualitativa e descritiva, com concentração na seleção de publicações sobre o tema, centralizando-se na análise de artigos científicos em Português, Espanhol e Inglês, publicados no ano de 2020 sobre o novo coronavírus, tema objeto de investigação. A bibliografia selecionada compõe as bases de dados SciELO ("Scientific Eletronic Library Online"), MEDLINE (Biblioteca Nacional de Medicina dos Estados Unidos da América) e Google Acadêmico. Na busca foram utilizados os descritores "COVID-19 and presos", "COVID-19 and penitenciárias", "COVID-19 and presídios", "confirmação de casos de COVID-19 em presos/detentos" e " COVID-19", assim como em sua tradução ao Inglês e ao Espanhol.

Como critérios de inclusão dos trabalhos, avaliou-se a data de publicação dos artigos científicos e a verificação de um ou mais descritores buscados em cada acervo de indexadores, razão pela qual o não atendimento de um desses requisitos impediu que o trabalho integrasse o presente estudo. Após a seleção do material, fez-se leitura detalhada, a fim de realçar dados, perspectivas, informações e conteúdos relevantes, desenvolvendo, em seguida, a síntese dos dados, interpretação e crítica de argumentos, exposições e resultados apresentados pelos trabalhos.

O levantamento sobre a regulamentação de medidas de enfrentamento ao novo coronavírus nas instalações penitenciárias, foi feito na home page do Departamento Penitenciário 
Nacional (Depen), do governo federal, nas abas de acesso "COVID-19 - Ações contra a Pandemia" e "Coronavírus no Brasil". Foram selecionadas as normativas e recomendações que mais se amoldavam com o tema deste trabalho, e em seguida procedeu-se à sua acurada leitura para apreender e aclarar as operações, medidas e estratégias lançadas no Sistema Penitenciário Federal.

\section{OS ESTABELECIMENTOS CORRECIONAIS FRENTE AO COVID-19: POSSÍVEIS MEDIDAS DE CONTINGÊNCIA}

As instalações correcionais são locais propícios para a disseminação de doenças infecciosas pela dificuldade de se adotar medidas de precaução e controle devido ao pequeno espaço das celas, e destas com outras, além do deficiente fluxo de ar nas instituições, o insatisfatório número de profissionais da saúde e de instalações e equipamentos compatíveis com o montante de detidos.

A distância social recomendada para evitar a propagação do contágio do novo coronavírus é extremamente difícil em entidades correcionais (Akiyama; Spaulding \& Rich, 2020), pois que muitos detentos são mantidos no mesmo espaço de confinamento, utilizando banheiros, chuveiros e lavanderias compartilhados e sentando ombro a ombro nos refeitórios. É preciso, portanto, alterar as práticas e a rotina dos detentos, para que se evite o alastramento do vírus em locais de profundo isolamento social.

Os presos apresentam maior propensão do que indivíduos que nunca habitaram cadeias e presídios para o desenvolvimento de doenças como câncer, diabetes, hipertensão, tuberculose, doença renal e cardiovascular, hepatite B e C e AIDS, ou consumo de substâncias tóxicas, cuja saúde debilitada aumenta o risco de desenvolver COVID-19 em grau grave, diante das péssimas condições humanitárias, estruturais e sanitárias encontradas nos presídios (Hawks; Woolhandler \& McCormick, 2020). Portanto, o novo coronavírus acentuou a crise que já havia sobre o sistema penitenciário, enfatizando a necessidade de uma mudança imediata na situação atualmente verificada.

Ademais, a população encarcerada possui origem variada, podendo ser inserida em penitenciárias e prisões já portando a doença, seja porque a localidade em que vivia ou frequentou estava enfrentando a moléstia ou porque essa se propagou na unidade correcional da qual fora transferido. Consoante uma pesquisa desenvolvida pelo "The Marshall Project" $e$ "The New York Times", cerca de 200.000 pessoas circulam pelas prisões dos Estados Unidos por semana (Flagg \& Neff, 2020).

Problemas como superlotação, ausência de atenção destinada à saúde dos detentos, segurança do estabelecimento prisional, insucesso da política de ressocialização, privação de serviços médicos de qualidade e compatível com o número de presos, também afligem o Brasil, que possui um total de 748.009 mil presos em unidades prisionais, segundo apurou o Levantamento Nacional de Informações Penitenciárias (Infopen), entre julho e dezembro de 2019. Conforme relatam Simanek, Malcoe e Nyitray (2020) uma única pessoa é suficiente para transmitir o novo coronavírus aos detentos e aos demais agentes. A falta de espaço, portanto, é um desafio 
a ser enfrentado para não se permitir o contato entre prisioneiros que testaram positivo para COVID-19, pelo período recomendado, ou de casos considerados suspeitos.

São considerados ainda alguns fatores que promovem a propagação de doenças infecciosas nas prisões: a idade do detento, sua escolaridade, condições clínicas pré-existentes, uso de drogas intravenosas, ventilação da área ocupada pelo prisioneiro, tempo em que ficará no sistema prisional, alocação celular, existência de prestação de serviços médicos na unidade e soltura de detentos para se respeitar a distância necessária entre aqueles ainda encarcerados (Simpson et al., 2019). Segundo o Infopen (2019), no sistema penitenciário nacional há 29.999 diagnósticos de HIV, sífilis, hepatite, tuberculose e outras doenças infecciosas.

A soltura de algumas pessoas que atualmente encontram-se encarceradas iria abrandar o número de pessoas que estão atualmente detidas para equalizá-lo com a capacidade de cada unidade prisional e minimizar as possibilidades de que o novo coronavírus nele ingresse ou facilmente se propague. A providência se mostra cada vez mais acertada, sobretudo analisando o índice de infecção por COVID-19 que existe na penitenciária Rikers Island, em Nova York, demonstrando ser muito maior às proporções de contaminação da sociedade em seus arredores (Rubin, 2020). Entretanto, um dos argumentos contrários para a liberação é a não apresentação do detento na entidade, quando exigir o seu retorno, em um momento em que a pandemia estiver contida e houver medidas eficazes de combate e tratamento.

Ao redor do mundo, muitas medidas estão sendo utilizadas como resposta para evitar a contaminação dentro das prisões, tais como a liberação de indivíduos próximos à conclusão do cumprimento de sua pena, concessão de livramento condicional, soltura de detidos por crimes praticados sem violência ou grave ameaça e daqueles que possuem maior inclinação para o desenvolvimento de caso clínico grave de COVID-19 (como, por exemplo, idosos, portadores de doença cardíaca, pulmonar, e renal, diabetes, imunossuprimidos, fumantes etc.) e prisão domiciliar, podendo estar acompanhado ou não de monitoramento eletrônico (Carroll, 2020).

Um fundamento para se admitir a libertação de um detento é o de que tal conduta representaria uma garantia à saúde não só para ele, mas também para toda a sociedade. A precariedade da saúde pública levanta a questão de que o risco que o preso enfrenta nas instalações de encarceramento também é um perigo a ser suportado pela comunidade, considerando que poderá contaminar outras pessoas que habitam regiões rentes à unidade prisional se for posto em quarentena domiciliar ou ainda intensificar a lotação de hospitais, colocando em risco inúmeras pessoas, inclusive aquelas responsáveis pelo seu transporte.

Outros argumentos favoráveis para a soltura de presos são apresentados por Hawks, Woolhandler e McCormick (2020), mencionando que a criminologia já demonstrou que os detentos idosos dificilmente promoverão alguma condição de risco à sociedade, além de que não se pode afirmar que os detentos com penas de longos anos ainda apresentam ameaça social, quando já cumpriram parcela considerável da sanção imposta.

Akiyama, Spaulding e Rich (2020) consideram que as medidas a serem adotadas pelos governos, levando em conta pandemias anteriores, como a causada pela gripe H1N1, são a libertação de presos com menor propensão de cometer crimes ao se encontrar novamente em 
sociedade, como idosos e enfermos; evitar a prisão de novas pessoas e a publicação de sentenças condenatórias com penas privativas de liberdade; a colocação em quarentena dos presos infectados e a realização de exames para o diagnóstico de possíveis infectados que com ele tiveram contato; internamento dos casos graves; reconhecimento dos funcionários contaminados pelo novo coronavírus, inclusive os já reestabelecidos, considerando que terão maior imunidade e estarão menos propensos à nova contaminação.

A análise da soltura poderá coincidir com as peculiaridades de cada preso, como, por exemplo, o perigo que representa à sociedade ou se enquadrar em alguma das situações de risco do vírus, devendo-se ponderar acerca da sua capacidade em manter a sua própria segurança e vivência em local apropriado. Muitos detentos marginalizados não possuem um lar ou outro local para ficar excluso, em distanciamento social, em atenção às medidas proferidas de prevenção e controle da doença, de modo que há cidades alugando quartos de hotel para que os moradores de rua e internos liberados fiquem abrigados (Stephenson, 2020).

Em uma análise comparada, o "Boreau of Prisions", que é responsável por 122 estabelecimentos correcionais nos Estados Unidos, não permite visitas sociais e de advogados nas instituições, como forma de deter a entrada do novo coronavírus em tais locais, contudo, apesar da adoção da medida referida, os casos de contaminação veem crescendo continuamente entre funcionários e detentos nas prisões situadas no Texas, Geórgia, Califórnia, Massachusetts, Michigan, Connecticut, Pensilvânia, Washington e em muitas outras localidades (RUBIN, 2020). Enquanto no condado de Cook, em Chicago, na data de 5 de abril, cerca de 234 internos foram diagnosticados com COVID-19, além de 78 funcionários (Stephenson, 2020).

Outros países conceberam a ideia da soltura de prisioneiros como uma medida eficaz para impossibilitar a transmissão do vírus, entre eles afigura-se o Irã, que proporcionou a soltura de aproximadamente 85.000 presos, e da mesma forma outros países vêm aderindo à ideia, como Austrália, Canadá, Etiópia, Alemanha e Reino Unido (Simpson \& Butler, 2020). Dessa maneira, compreende-se que obstar o contato entre os sujeitos é uma medida mais eficaz do que lutar contra uma pandemia já alastrada, razão pela qual as orientações devem ser emitidas e adotadas antes de haver a infecção nos estabelecimentos carcerários (Simpson \& Butler, 2020).

Assim, tem-se que os interesses em se admitir que o sujeito permaneça nas unidades correcionais com o propósito de preservar a segurança pública, se contrapõem com o direito de manutenção de sua saúde, pois que estará submetido a um alto risco de infecção, por estar vulnerável e exposto ao vírus. É preciso que tal população receba uma análise diferenciada e benevolente das autoridades competentes, não Ihes sujeitando a tal condição indigna e desprezível.

\section{RESULTADOS E DISCUSSÕES}

A seguir se apresentará algumas normativas que contemplam operações e práticas de enfrentamento ao novo coronavírus, mencionando-se a espécie de regulamentação, a data de publicação e o órgão expedidor, dentro do Sistema Penitenciário Federal, para propiciar a proteção e o resguardo da saúde de presos, servidores e demais cooperadores. 
Assim sendo, para melhor averiguar as ações, necessidades e condições das instalações do Sistema Penitenciário Federal, o Diretor-Geral do Depen publicou a Portaria no 135, de 28 de fevereiro de 2020, determinando a criação de um grupo de trabalho (GT), composto por sete integrantes e com duração de 60 dias, devendo realizar reuniões semanais para estudo e verificação de possíveis comportamentos a serem implementados em tais instalações.

O Conselho Nacional de Justiça (CNJ) emitiu a Recomendação no 62, em 17 de março de 2020, de vigor por prazo de 90 dias, determinando algumas medidas de prevenção à COVID-19 no sistema de justiça criminal e ao âmbito socioeducativo. $O$ art. 4음 da diretriz estatui que os magistrados devam, durante o processo criminal, proceder à revisão das prisões provisórias, preferindo mulheres gestantes, lactantes e mães ou responsável de criança de até 12 anos de idade ou qualquer adolescente que se enquadre no grupo de risco; que estiverem em unidade com superlotação, que não disponham de sistema de saúde adequado, que estejam interditadas ou que apresentem estrutura que permita a propagação do vírus; e os detidos por prisão preventiva que tenham extrapolado o prazo de 90 dias, ou em razão de prática de atos infracionais sem violência ou grave ameaça. O mesmo dispositivo ainda aduz que o julgador deverá suspender pelo período de 90 dias a obrigação do dever de apresentação periódica a juízo dos indivíduos em liberdade provisória e suspensão condicional do processo; e a prisão preventiva deve ser apercebida como medida excepcional (BRASIL, 2020).

Em seu art. 50, a regulamentação ainda prevê que os julgadores encarregados pela execução penal concedam a saída antecipada dos prisioneiros em regime fechado e semiaberto, em alusão à Súmula Vinculante $\mathrm{n}$ o 56 do Supremo Tribunal Federal (STF), se tratando de mulheres gestantes, lactantes e mães ou responsável de criança de até 12 anos de idade ou qualquer adolescente que se enquadre no grupo de risco, ou que estiverem em unidade com superlotação, que não disponham de sistema de saúde adequado, ou que estejam interditadas ou que apresentem estrutura que permita a propagação do vírus; além de possibilitar a concessão de prisão domiciliar para os que se encontram em regime aberto e semiaberto, assim como daqueles considerados casos suspeitos ou confirmados de COVID-19, quando não houver ambiente para o isolamento na unidade prisional; suspensão temporária de comparecimento regular em juízo de pessoas em regime aberto, prisão domiciliar, penas restritivas de direitos e suspensão da execução da pena (sursi), concedidas pelo prazo de 90 dias (BRASIL, 2020).

O art. 11 dispõe regras de visitação aos estabelecimentos prisionais e unidades socioeducativas, precipuamente a elaboração de um plano de contingência pelos gestores, devendo abarcar a higienização dos espaços de visitação, a entrega de máscaras e demais equipamentos de proteção, a proibição da entrada daqueles que apresentem os sintomas desencadeados pela COVID-19 e dispor dias e horários de visitação diferentes a fim de reduzir o fluxo de pessoas. $\mathrm{O}$ art. 13 prescreve que os magistrados devem encaminhar os montantes resultantes das penas pecuniárias durante o estado de emergência para a aquisição de produtos de limpeza e proteção da saúde (BRASIL, 2020).

A Portaria no 143, de 25 de março de 2020, do Ministério da Justiça e Segurança Pública, em seu art. 20 permite a reformulação e revisão dos planos de aplicação das ações destinadas a financiar e apoiar as atividades e os programas de modernização e aprimoramento dos sistemas 
penitenciários, a serem custeados com os recursos do repasse fundo a fundo do exercício de 2019, de forma a adequá-los à situação emergencial dos efeitos da pandemia do coronavírus (COVID-19) nos ambientes prisionais, sendo tal montante remetido para a aquisição de materiais e no emprego das medidas emitidas em tal âmbito. Ainda, a Resolução no 313, de 19 de março de 2020, emanada pelo Conselho Nacional de Justiça (CNJ), estatui, em seu art. 9o, que o valor pecuniário advindo de penas de prestação pecuniária, transação penal e suspensão condicional do processo devem ser destinados para a aquisição de instrumentos médicos necessários ao enfrentamento da pandemia de COVID-19 (BRASIL, 2020).

Neste sentido, a Nota Técnica Conjunta no 1, de 28 de abril de 2020, elaborada pelo CNJ e pelo Conselho Nacional do Ministério Público (CNMP) orienta que os investimentos do Fundo Penitenciário Nacional (Funpen) sejam destinados urgentemente à compra de materiais de limpeza, para higienização dos espaços ocupados pelos detentos; de equipamentos de proteção individual aos privados de liberdade e aos servidores; de alimentos; e de instrumentos para serem empregados no atendimento preventivo, como, por exemplo, exames médicos, testes laboratoriais, coletas e vacinas. Ainda, a mencionada Nota Técnica Conjunta apresenta que o CNJ e o CNMP celebraram um Termo de Cooperação na data de 27 de abril de 2020 para analisar o plano de utilização dos recursos do Funpen, pela antecedente aprovação do Departamento de Monitoramento e Fiscalização do Sistema Carcerário e do Sistema de Execução de Medidas Socioeducativas, do CNJ (BRASIL, 2020).

Em referida Nota Técnica, se orienta a criação de ambientes para isolamento e tratamento dos presos diagnosticados com o novo coronavírus, mencionando que o Depen, por intermédio do Ofício no 806, submeteu ao Conselho Nacional de Política Criminal e Penitenciária uma proposta de criação de vagas e instalações temporárias, deixando de observar as Diretrizes Básicas para Arquitetura Penal (Resolução no 9/2011, do CNPCP) para utilizar estruturas metálicas e contêineres. Contudo, o CNJ e o CNMP se manifestaram em contrário a tal sugestão, haja vista as condições precárias e descumpridoras de direitos humanos por elas oferecidas, ressaltando que apesar de se estar enfrentando uma pandemia, as normas de conforto mínimas e garantias asseguradas aos privados de liberdade não podem ser inobservadas (BRASIL, 2020).

A Portaria no 135, expedida em 18 de março de 2020, pelo Ministério da Justiça e Segurança Pública, estabelece medidas mínimas e cogentes que devem ser adotadas pelos administradores dos alojamentos prisionais, tais como a redução máxima da admissão de visitantes e advogados (I); o distanciamento dos demais presos daqueles provenientes de transferências ou objeto de prisão em flagrante (II); a redução ou limitação das transferências entre instalações prisionais (III); a instituição de áreas próprias de isolamento de detentos com sintomas de gripe (IV); o distanciamento de presos maiores de 60 anos e que apresentem doença crônica (V); a suspensão de audiências ou, no caso daquelas indispensáveis e urgentes, sua realização por videoconferência (VI); limpeza diária das celas e criação de campanhas educacionais para os servidores, visitantes e detentos sobre os métodos de prevenção (VII e VIII); suspensão ou redução de atividades que acarretam aglomeração dos privados de liberdade (trabalho, educação e religiosa), promovendo o aumento do período destinado ao banho de sol (IX e X); suspensão da saída temporária de presos, somente permitido quando não for possível, após triagem por equipe de saúde em sua volta (XI); 
realização de mutirões carcerários virtuais envolvendo Poder Judiciário, Ministério Público, Defensorias e a Ordem dos Advogados do Brasil (OAB) para a análise criteriosa de benefícios pendentes e ajustamento de progressões de regime de cumprimento das penas (XII); suspensão de saídas temporárias, ou, no caso de impossibilidade, triagem dos presos por equipe de saúde habilitada no retorno (XIII); e suspensão de férias e licenças de servidores do sistema prisional pelos próximos 90 dias (XIV).

Em alusão a tais preceitos, o Diretor do Sistema Penitenciário Nacional, elaborou a Portaria no 5, de 16 de março de 2020, determinando, em seu art. 1으, a suspensão de 30 dias das visitas, assistência por advogado, atividades educacionais e de trabalho, além da execução de ações de apoio religioso e escoltas de detentos, sendo que a assistência de advogado somente poderia ocorrer em caso de urgência e não se tratar de prazos processuais suspensos. Já em seu art. 2oㅡ, prevê que a organização prisional deve fazer com que os prisioneiros idosos e que dispõem de doenças crônicas sejam isolados completamente durante suas movimentações internas. Da mesma forma dispõe a Portaria no 12, de 22 de abril de 2020, mantendo tais diretrizes por mais 30 dias (BRASIL, 2020).

Segundo a Nota Técnica no 23, expedida em 5 de março de 2020, pela Coordenação de Saúde do Depen, nas 1.412 unidades prisionais existentes atualmente no Brasil, 856 dispõem de consultório médico, cerca de 726 de consultório odontológico, 230 detêm salas de enfermarias com solário e 462 contam com sala de coleta de material para laboratório. Além disso, a referida Nota Técnica apresentou que o Brasil possui 0,9 médicos e 1,27 odontólogos a cada mil detentos, e que os centros de detenção estão se preparando para a pandemia de COVID-19 "através de orientações técnicas, aquisição de insumos e ainda através da disponibilização de apoiadores e mobilizadores sociais do Projeto Prisões Livres de Tuberculose para atuar nas ações de educação em saúde e auxiliar na elaboração dos planos de contingência" (BRASIL, 2020, p. 3). Mencionada Nota Técnica ainda complementa que a Depen adiantou a vacinação contra a gripe influenza nas instituições prisionais, como uma prática de confronto à propagação do novo coronavírus, tanto para pessoas privadas de liberdade como para os servidores (BRASIL, 2020).

A Informação no 11, de 9 de abril de 2020, elaborada pela Assessoria de Assuntos Estratégicos do Depen, apresentou que, em 47 países levantados, 89\% dos países afetados pela COVID-19 logram de um protocolo específico de ações de combate à pandemia dentro de unidades prisionais, e 31 países suspenderam total ou parcialmente as visitas aos prisioneiros, como, por exemplo, o Brasil. Ressalta-se que esta foi uma das primeiras medidas consagradas pelo país em reação ao avanço da pandemia em seu território, a fim de intensificar o isolamento e evitar que indivíduos externos portem o vírus para dentro das prisões. Ainda, segundo a informação elaborada, o Brasil vem efetivamente adotando videoconferências para proporcionar visitas virtuais e assessoria jurídica, assim como para fins educativos e religiosos (BRASIL, 2020).

Além disso, o Depen possui uma unidade de Monitoramento de Deteç̧ão/Suspeita do Coronavírus nos Sistemas Penitenciários Brasileiros, cujos dados de 12 de maio de 2020 relatam existir 603 casos detectados e 23 óbitos nos sistemas prisionais, além de 376 casos suspeitos no Brasil, sendo que não há registros confirmados para a doença no Sistema Penitenciário Federal. Inclusive, contam com 2.323 testes realizados em detentos para o diagnóstico de COVID-19 no 
país, o que representa um número extremamente reduzido, não sendo o suficiente para proporcionar a verificação da situação real de contaminação dentro das penitenciárias (BRASIL, 2020).

A Coordenação-Geral de Assistências nas Penitenciárias desenvolveu as Medidas de Controle e Prevenção do Novo Coronavírus no Sistema Penitenciário Federal, em 02 de março de 2020 , sendo que todas devem ser obrigatoriamente concretizadas. O plano estabelece que os sistemas prisionais federais devam realizar ações de triagem para a identificação de casos suspeitos e prováveis de COVID-19, interrogando todas as pessoas que adentram na instalação penitenciária, a fim de evitar que pessoas com sintomas da doença nela ingressem (BRASIL, 2020).

Entre as medidas de isolamento e prevenção para servidores e terceirizados, caso tenham realizado viagens internacionais, deverão proceder às suas atividades de forma remota, até esgotar os 14 dias seguintes ao término da viagem; enquanto que para as viagens nacionais, deverão exercer de maneira temporária as atividades inerentes à sua função em regime "home office" até o sétimo dia de sua volta; ao passo em que os servidores com suspeita ou probabilidade da doença não devem retornar ao trabalho, devendo seu afastamento ser comunicado aos gestores por e-mail (BRASIL, 2020).

Em relação ao interno com suspeitas de COVID-19, a esse deve ser fornecida máscara cirúrgica e ser mantido em sua cela, em isolamento, até se obter um diagnóstico definitivo sobre a sua infecção. Sendo os sintomas leves, o isolamento deverá ocorrer dentro do próprio estabelecimento prisional, com vigilância dos profissionais de saúde nela alocados; tempo em que os casos graves ou com comorbidades deverão ser repassados ao sistema de saúde do município em que se encontra localizado. Os profissionais envolvidos na escolta deverão se precaver, garantindo a ventilação do veículo de transporte, e dispondo de máscaras e luvas, quando houver contato físico com o detento, além de outros Equipamentos de Proteção Individuais (EPI's) que se fizer necessário, e a higienização das mãos frequentemente, seguindo os cinco passos. Concluído o procedimento de escolta, o automóvel deverá ser limpo e desinfetado com álcool hidratado $70 \%$, hipoclorito de sódio ou outro antisséptico (BRASIL, 2020).

No isolamento do interno que apresente caso clínico suspeito ou confirmado, este deve ser mantido em sua cela, em distanciamento dos demais internos, restringindo o tráfego de agentes em suas proximidades e que com ele entrarão em contato - neste caso, mediante à utilização de máscaras e luvas -, estando tais servidores restritos ao relacionamento aos detentos com registros de suspeita ou confirmação de COVID-19. Deve-se fornecer álcool em gel na entrada do espaço de isolamento, e recomenda-se que a máscara seja trocada sempre que estiver molhada ou com secreções, devendo ser descartada logo após o uso e com a seguinte higienização das mãos (BRASIL, 2020).

Deve-se evitar tocar em qualquer superfície próxima ao privado de liberdade suspeito ou confirmado, ou mesmo fora da área de afastamento do paciente com os EPI's, como teclado de computador, portões e munições. O indivíduo que teve contato com caso suspeito deve permanecer em estado de vigilância por 14 dias, monitorando sua saúde e a presença dos sinais da doença, devendo recorrer aos serviços de saúde caso tais se manifestem em seu organismo em 
grau grave. Caso os internos não disponham de EPI's, os servidores do sistema prisional que com eles tiverem contato devem utilizar aventais, luvas, máscara N-95 e óculos de proteção individual (BRASIL, 2020).

São normas a serem seguidas por todos os indivíduos da unidade prisional: ao tossir ou espirrar, deve-se cobrir o nariz e a boca com lenço de papel ou com o cotovelo flexionado, emprego de lenços de papel descartáveis e posterior descarte imediatamente após o uso, abster-se de contato com olhos, nariz e boca e higienizar as mãos constantemente com água e sabão por no mínimo 20 segundos ou álcool em gel hidratado 70\%. Ademais, os espaços devem ser bem ventilados e desinfetados regularmente. É dever da instalação conscientizar e orientar a todos sobre os sintomas e medidas a serem tomadas a respeito do novo coronavírus (BRASIL, 2020).

Em 15 de março de 2020, a OMS lançou o manual "Preparação, Prevenção e Controle do COVID-19 em Prisões e outros Locais de Detenção" estabelecendo variadas diretrizes que foram atendidas pelas normas internas expedidas pelo Brasil como reação à pandemia de COVID-19. Tal guia alerta para a importância do uso consciente da máscara cirúrgica como prática de precaução, no entanto, essa, isoladamente, não é eficaz na luta contra a propagação do novo coronavírus, ressaltando o acolhimento simultâneo de outras práticas de prevenção.

Cumpre ainda destacar que a OMS (2020) também alvitra pela quarentena do preso que viajou ou viveu em região com grande transmissão do vírus ou que teve contato com caso confirmado de COVID-19, durante o período de 14 dias, devendo fazer uso de máscara durante o seu descolamento para o local de isolamento, e ser examinado por equipe médica duas vezes ao dia, com avaliação de sua temperatura e dos sinais da doença.

Em abril, o Depen lançou a primeira edição do Manual de Recomendações para Prevenção e Cuidado da COVID-19 no Sistema Prisional Brasileiro, expondo informações básicas sobre o vírus transmissor, sintomas e as formas de contágio. Entre as medidas de prevenção, recomenda evitar a contaminação, que ocorre mediante o contato com pessoas e superfícies infectadas e partículas soltas no ar, com o uso de máscara, separação do contato com outras pessoas, limpeza das mãos e esquivar o toque na face com as mãos. Orienta ainda, como ações para se minimizar os efeitos deletérios do isolamento social, a entrega de cartas nas unidades prisionais e a utilização do sistema de som para a comunicação de notas e recados religiosos (BRASIL, 2020). Neste diapasão, a Portaria no 10 do Diretor do Sistema Penitenciário Federal, de 02 de abril de 2020, regulamenta a carta virtual, que estará em vigor pelo período em que as visitas físicas ficarem suspensas, e que não substitui a carta recebida através dos Correios (carta social), com a finalidade de propiciar comunicação mais célere dos detentos com os membros de sua família (BRASIL, 2020).

São outras medidas de proteção citadas pelo Manual: o distanciamento mínimo de 1,5 m entre os prisioneiros em todas as atividades diárias, inclusive em refeições; higienização dos equipamentos compartilhados no plantão, como armamentos, algemas, HT's, chaves, e quaisquer outros instrumentos de uso individual utilizado continuamente, podendo tal limpeza ocorrer com álcool hidratado $70 \%$ ou com água sanitária, segundo orientações do fabricante. Adverte-se também para que se desinfete o colete, armamento e cinto de guarnição, sendo que, ao chegar 
em casa, os calçados devem ser mantidos na área externa da residência ou em local reservado (BRASIL, 2020).

O mencionado Manual orienta que a higienização dos espaços prisionais ocorra com solução de água e sabão ou desinfetante ao menos uma vez ao dia, incluindo limpeza do chão, portas, paredes e grades, e a área ocupada pelos profissionais penitenciários também deve obedecer à recomendação de higienização diária, a cada mudança de turno (BRASIL, 2020).

Acima se verificou algumas ações, projetos e programas adotados no Sistema Penitenciário Federal, e outros aplicados no sistema carcerário como um todo, para o combate da pandemia de COVID-19, a fim de adequar o serviço e a rotina dos detentos às recomendações emitidas pelo Ministério da Saúde e órgãos epidemiológicos com o propósito de refrear o alastramento do vírus.

\section{CONSIDERAÇÕES FINAIS}

Auferiu-se que o Depen e demais órgãos da administração pública expediram diversas normativas para regulamentação do trabalho de seus servidores e para disciplinar o plano de ações com as medidas a serem aplicadas aos privados de liberdade, como a suspensão de visitas, atividades educacionais e trabalho, e liberação dos detentos que apresentaram maiores propensões de desenvolver COVID-19 em grau grave. Tais ações foram extremamente necessárias e eficientes para se preservar a vitalidade, integridade e dignidade dos detentos, devendo dispor de equipamentos de proteção e insumos suficientes para tais orientações serem observadas.

Muitos critérios precisam ser sopesados pelos gestores das unidades prisionais, autoridade judicial com competência na fase de execução da pena e membros do Poder Executivo, como a segurança da população carcerária e também da sociedade em geral, a saúde dos detentos e da população externa e o bem-estar e incolumidade mental dos presos frente à intensificação da exclusão sofrida em decorrência das medidas de distanciamento social, entre outros.

Apesar de o Sistema Penitenciário Federal dispor de procedimentos, sistema de vigilância aprimorada e de capacitada estrutura, além da rotina carcerária que promove o isolamento de $22 \mathrm{~h}$ diárias, condições estas diversas das demais unidades pertencentes ao sistema prisional brasileiro, a exclusão social em geral propicia o avanço de contaminações pelo novo coronavírus. Contudo, tem-se que a rigorosa metodologia e rotina empregadas nas penitenciárias federais evitaram a introdução e o alastramento do vírus internamente.

De outra forma, a existência de equilíbrio entre as medidas determinadas também é crucial para não se destruir a ordem social e se preservar a paz, fazendo com que os indivíduos transgressores do sistema de normas recebam sanção compatível com o seu delito e capaz de gerar ressocialização, demonstrando a autoridade do Estado na aplicação e execução da pena. É por isso que buscar conter a entrada do vírus nas prisões é a principal medida adotada, contudo, ainda assim essa se sucedeu, razão pela qual as medidas devem ser mais rigorosas e efetivadas, reforçando o conhecimento transmitido acerca da doença e a importância do atendimento das providências emitidas. 
Entretanto, não se pode eliminar a análise humanitária a respeito de tais sujeitos, e por isso o Governo Federal demonstrou condolência em diversas normativas, contemplando a flexibilização da reclusão imposta aos sujeitos que cumprem pena em regime fechado e semiaberto, para Ihes propiciar condições mais dignas de confinamento. Tais medidas coincidem com aquelas abarcadas por outros países, na tentativa de evitar a contaminação em massa de presos e funcionários de tais estabelecimentos prisionais.

\section{REFERÊNCIAS}

Akiyama, M. J.; Spaulding, A. C.; Rich, J. D (2020). Flattening the Curve for Incarcerated Populations - Covid-19 in Jails and Prisons. The New England Journal of Medicine, Massachusetts Medical Society, 382 (22), 2075-2077. DOI: 10.1056 / NEJMp2005687.

BRASIL (2020). Conselho Nacional de Justiça. Conselho Nacional do Ministério Público. Nota Técnica Conjunta no 1, de 28 de abril de 2020. Conselho Nacional de Justiça e Conselho Nacional do Ministério Público, Brasília.

BRASIL (2020). Conselho Nacional de Justiça. Recomendação no 62, de 17 de março de 2020. Conselho Nacional de Justiça, Brasília.

BRASIL (2020). Conselho Nacional de Justiça. Resolução no 313, de 19 de março de 2020. Conselho Nacional de Justiça, Brasília.

BRASIL (2020). Departamento Penitenciário Nacional (Depen). Coordenação-Geral de Assistências nas Penitenciárias. Medidas de Controle e Prevenção do Novo Coronavírus no Sistema Penitenciário Federal, de 02 de março de 2020. Departamento Penitenciário Nacional, Brasília.

BRASIL (2020). Departamento Penitenciário Nacional (Depen). Levantamento Nacional de Informações Penitenciárias. Dezembro de 2019. Departamento Penitenciário Nacional, Brasília.

BRASIL (2020). Departamento Penitenciário Nacional (Depen). Monitoramento de Detecções/Suspeitas do Coronavírus nos Sistemas Penitenciários Brasileiros. Departamento Penitenciário Nacional (Depen), Brasília.

BRASIL (2020). Ministério da Justiça e Segurança Pública. Portaria no 5, de 16 de março de 2020. Brasília: Ministério da Justiça e Segurança Pública, Brasília.

BRASIL (2020). Ministério da Justiça e Segurança Pública. Portaria no 10, de 02 de abril de 2020. Ministério da Justiça e Segurança Pública, Brasília.

BRASIL (2020). Ministério da Justiça e Segurança Pública. Portaria no 12, de 22 de abril de 2020. Ministério da Justiça e Segurança Pública, Brasília.

BRASIL (2020). Ministério da Justiça e Segurança Pública. Portaria no 135, de 28 de fevereiro de 2020. Ministério da Justiça e Segurança Pública, Brasília. 
BRASIL (2020). Ministério da Justiça e Segurança Pública. Portaria no 143, de 25 de março de 2020. Ministério da Justiça e Segurança Pública, Brasília.

BRASIL (2020). Ministério da Justiça e Segurança Pública. Departamento Penitenciário Nacional (Depen). Coordenação de Saúde. Nota Técnica no 23, de 05 de abril de 2020. Coordenação de Saúde do Depen, Brasília.

BRASIL (2020). Ministério da Justiça e Segurança Pública. Departamento Penitenciário Nacional (Depen). Assessoria de Assuntos Estratégicos do Departamento Penitenciário Nacional. Informação no 11, de 09 de abril de 2020. Assessoria de Assuntos Estratégicos do Departamento Penitenciário Nacional, Brasília.

BRASIL (2020). Departamento Penitenciário Nacional (Depen). Recomendações para Prevenção e Cuidado da COVID-19 no Sistema Prisional Brasileiro (1a ed.). Ministério da Saúde e Ministério da Justiça e Segurança Pública, Brasília.

Carroll, J. (2020). Pretrial Detention in the Time of COVID-19. Northwestern University Law Review, 115, 59-87. https://papers.ssrn.com/sol3/papers.cfm?abstract_id=3576163.

Croda, J. H. R.; Garcia, L. P (2020). Resposta imediata da Vigilância em Saúde à epidemia da COVID19. Revista Epidemiologia e Serviços de Saúde, 29 (1), 20-22. DOI: http://dx.doi.org/10.5123/s1679-49742020000100021.

Farias, H. S. (2020). O avanço da COVID-19 e o isolamento social como estratégia para redução da vulnerabilidade. Revista Brasileira de Geografia Econômica, a. IX (17), 1-12. DOI: https://doi.org/10.4000/espacoeconomia.11357.

Flagg, A.; Neff, J. (31 mar., 2020). Why Jails Are So Important in the Fight Against Coronavirus. The Marshall Project. Acesso em 5 de maio de 2020 de https://www.themarshallproject.org/2020/03/31/why-jails-are-so-important-in-the-fightagainst-coronavirus.

Garcia, L. P.; Duarte, E. (2020). Intervenções não farmacológicas para o enfrentamento à epidemia da COVID-19 no Brasil. Revista Epidemiologia e Serviços de Saúde, 29 (2), 1-4. https://doi.org/10.5123/s1679-49742020000200009.

Hawks, L.; Woolhandler, S.; Mccormick, D. (2020). COVID-19 in Prisons and Jails in the United States. Journal of the American Medical Association, 180 (8), 1041-1042. DOI: 10.1001 / jamainternmed.2020.1856.

Keller, A.; Wagner, B. (2020). COVID-19 and immigration detention in the USA: time to act. The Lancet Public Health, 5 (5), 245-246. DOI: https://doi.org/10.1016/S2468-2667(20)30081-5.

Medeiros, E. A. S. (2020). Desafios para o enfrentamento da pandemia COVID-19 em hospitais universitários. Revista Paulista de Pediatria, 38, 1-2. DOI: https://doi.org/10.1590/19840462/2020/38/2020086. 
Montermerli, R. (2020). Os desafios da Itália na emergência do coronavírus. Revista Brasileira de Geografia Econômica, a. IX (17), 1-16. DOI: https://doi.org/10.4000/espacoeconomia.11312.

Organização das Nações Unidas - ONU (1990). Princípios básicos para o tratamento de prisioneiros. Resolução no 45/111 da Assembleia Geral, de 14 de dezembro de 1990. https://www.ohchr.org/en/professionalinterest/pages/basicprinciplestreatmentofprisoners. asp.

ORGANIZAÇÃO MUNDIAL DA SAÚDE - OMS (2020). Preparedness, prevention and control of COVID-19 in prisons and other places of detention, de 15 de março de 2020. http://www.euro.who.int/_data/assets/pdf_file/0019/434026/Preparedness-preventionand-control-of-COVID-19-in-prisons.pdf?ua=1.

Rubin, R. (2020). The Challenge of Preventing COVID-19 Spreadin Correctional Facilities. Journal of the American Medical Association, 323 (18), 1760-1761. DOI: 10.1001 / jama.2020.5427.

Silva, A. A. M. (2020). Sobre a possibilidade de interrupção da epidemia pelo coronavírus (COVID19) com base nas melhores evidências científicas disponíveis. Revista Brasileira de Epidemiologia, 23, 20-21. DOI: https://doi.org/10.1590/1980-549720200021.

Silva, J. B.; Muniz, A. M. V. (2020). Pandemia do Coronavírus no Brasil: Impactos no Território Cearense. Revista Brasileira de Geografia Econômica, a. IX, (17). DOI: https://doi.org/10.4000/espacoeconomia.10501.

Simanek, A. M.; Malcoe, L. H.; Nyitray, A. G. (07 abr., 2020). Declaration to Protect Incarcerated Persons, Correctional Staff, and Wisconsin Communities from COVID-19. Joseph J. Zilber School of Public Health, 1-8. Acesso em 10 de maio de 2020 de https://www.acluwi.org/sites/default/files/affidavit_aclu_wi_prisons.pdf.

Simpson, P. L.; Butler, T. (2020). COVID-19, prison crowding, and release policies. The BMJ, 369, (1551), 1-2. DOI: https://doi.org/10.1136/bmj.m1551

Simpson, P. L., et al. (2019). Prison cell spatial density and infectious and communicable diseases: a systematic review. BMJ Open, 9, (7), 1-10. DOI: 10.1136 / bmjopen-2018-026806.

Stephenson, J. (07 abr., 2020). COVID-19 Pandemic Poses Challenge for Jails and Prisons. Journal of the American Medical Association. Acesso em 27 de abril de 2020 de https://jamanetwork.com/channels/health-forum/fullarticle/2764370.

\section{COMO CITAR ESTE ARTIGO:}

Sousa, T. A. L. de (2020). As medidas adotadas no sistema penitenciário federal no combate à pandemia de COVID-19. Holos. 36(5), 1-15.

\section{SOBRE OS AUTORES}

\section{T. A. L. DE SOUSA}

Possui graduação em Análise e Desenvolvimento de Sistemas pela União Educacional de Brasília (2004). 
Técnico em Montagem e Assistência Técnica em Microcomputadores, SENAI (2002). Pós-Graduação Lato Sensu em Administração Pública. Mestrando em Administração Pública - UNB. Atualmente servidor público federal do Ministério da Justiça e Segurança Pública. E-mail: aluisio83@outlook.com ORCID ID: https://orcid.org/0000-0002-8648-7555

Editor(a) Responsável: Leandro Costa

Pareceristas Ad Hoc: LENINA SILVA E KALYANE OLIVEIRA

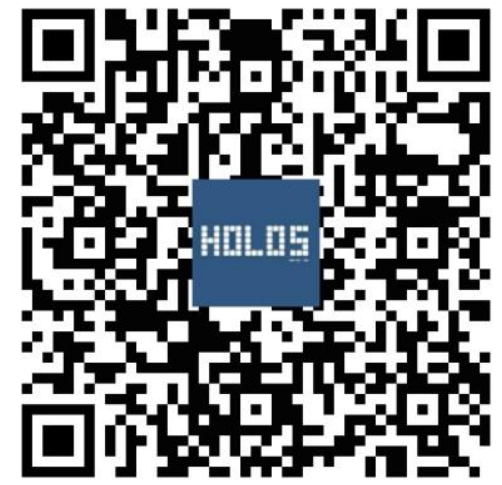

